Article

\title{
Ecological Prototypes: Initiating Design Innovation in Green Construction
}

\author{
Defne Sunguroğlu Hensel
}

Department of Integrated Planning and Industrial Building, Faculty for Civil Engineering,

Vienna University of Technology, 1040 Vienna, Austria; defne.hensel@tuwien.ac.at; Tel.: +49-160-339-1301

Received: 6 June 2020; Accepted: 16 July 2020; Published: 21 July 2020

check for updates

\begin{abstract}
This article identifies a gap in the approaches to Green Construction (GC), and initiates a line of research in the area of the so-called "ecological prototypes". Ecological prototypes, stands for a new type of GC, which are integrated and adaptive systems of design, construction and practices that link architecture, horticulture and agriculture, landscape and ecology. This type of system greatly expands the existing GC design space with the aim to tackle environmental challenges in the context of rapid urbanization. This new type of GC seeks to reconcile the different environmental needs and goals, and balance intensification and restoration trade-offs. They are considered as a key strategy for supporting ecosystems and the delivery of ecosystem services, especially in degraded peri-urban and urban contexts. This effort commences with a review of selected historical cases that have evolved over time as vital part of horticultural and agricultural systems. These historical studies can both inform future research on the development of ecological prototypes and aid their design. Following the examination of selected cases and a field survey, the role of information modelling and data-driven computational methods in designing ecological prototypes is discussed. The decision support system for this new type of GC based on information and knowledge modelling (computational ontologies) is given a particular attention. Finally, further research questions and steps are outlined.
\end{abstract}

Keywords: green construction; agriculture; horticulture; information modelling; decision support system

\section{Introduction}

Urbanization is one of the most significant environmental challenge of the 21st century. Construction causes loss of agricultural and forest landscapes, damage to ecosystems, depletion of natural resources, decline of biodiversity and climate change [1,2]. Numerous studies highlight the importance of ecosystems [3] and the adverse consequences of environmental degradation on the health and wellbeing of humans [4], especially in urban contexts [5]. Land use change and degradation through urban expansion and densification threatens food security and the fundamental benefits derived from human-nature relationship [6]. However, construction can also be an enabler of Green Infrastructure (GI) for the restoration of degraded urban environments [7].

Peri-urban agriculture (UPA) is a critical GI component that plays a key role in land restoration. The latter has been shown to be of central importance for achieving various sustainable development goals (SDG), by improving building's ecological footprint [8]. Even though agriculture is the most important driver of land conversion, it is also a land system vulnerable to urbanization [9]. Increasing lack of space in cities and urban expansion is leading to a growing demand for architectural integration of agriculture and horticulture to bring GI benefits into architectural and urban space [10]. This makes it possible to enable ecosystem services indoors, outdoors and in transitional spaces [11].

Minimizing the environmental impact of buildings through sustainable use of natural resources, boosting agricultural production and nature in cities to maintain biodiversity and ecosystem services, are now the primary motivations behind green construction (GC). This has already led to the emergence 
of new green buildings, i.e., vertical forests like the Bosco Verticale in Milan by Stefano Boeri or the Biodiversity Tower M6B2 in Paris by Eduard Francois. There exists also a growing interest in ways in which the combination of green roofs and facades can act as green conservation tools, enhancing biodiversity, as well as more broadly, the integration of biotic and abiotic components of green buildings [12].

However, in cases where GI has been involved in improving environmental performance of buildings, GC has either been limited to intensive agriculture or extensive horticulture. The result is typically resource and maintenance intensive, and commonly provides limited ecosystem functions.

A wide range of historical constructions and practices show that human constructions and activities are not necessarily harmful to the environment. Instead, they can be of vital importance for the protection, support and enhancement of local ecosystems and the delivery of services. Such cases show that land and soil protection, environmental heterogeneity and species richness, wildlife conservation, land productivity and the prevention of the spread of invasive species is directly linked with the traditional constructions and associated farming practices [13,14].

Today's GCs are primarily designed to cater for the needs of agricultural intensification or for making cities greener. These operate differently than their earlier predecessors and occupy different regions in the GC design space (Figure 1). Some of these constructions facilitate intensive agriculture, but require high external input and maintenance. These tend towards fully-closed systems of food production that are decoupled from their natural environment (Region 1 top left $(+/-)$ ). Other structures enable extensive horticulture with considerable or zero external input. These types often provide ecosystem functions to a lesser extent (Region 2 bottom left (-/-)). Historical agricultural constructions enable sustainable extensive cultivation in challenging environments. They provide solutions that work with local climatic and ecological conditions, and available materials and renewable resources, and do not depend on external input, i.e., energy. These range from provisions for single plants, to extensive farming at the landscape scale, and urban farming with ecological value (Region 3 bottom right $(-/+)$ ). Ecological prototypes constitute the next generation GC systems (Region 4 top right $(+/+)$ ) [15]. This is the area where research is needed for context-specific design, construction and practices that can simultaneously enable integrated land-use intensification (agricultural/horticultural and residential) and land restoration (by incorporating strategies that facilitate avoiding, reducing and reversing land degradation) to reconcile the different environmental needs, goals and interactions.

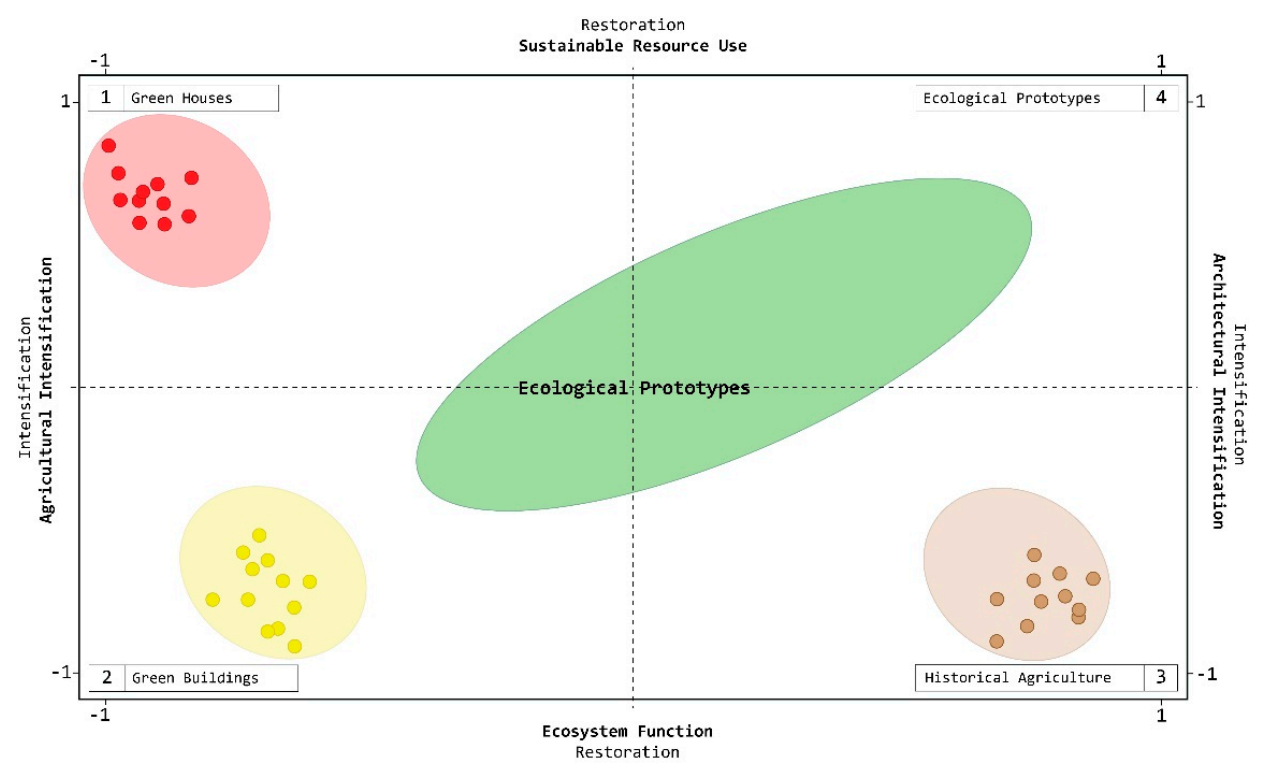

Figure 1. The green construction (GC) design space in principle generates four quadrants: Greenhouses (top left); Green buildings (bottom left); Historical agricultural systems (bottom right) and Ecological prototypes (top right). 
This article commences by examining selected historical structures and practices that belong to the third group but can contribute valuable knowledge to inform research on ecological prototypes. These cases are presented in Section 3.

In the discussion section, the research thus far is examined and further research steps are outlined. Special attention is given to the structuring of information and ultimately modelling knowledge gathered from a broad range of case studies. The aim is to collect, correlate and integrate the gathered knowledge in an information model (computational ontology) in future research phases [16]. This information model is a critical component for bringing green construction intelligence into data-driven design. This will lead to the development of a design decision support system that will assist the exploration of the GC design space, and the design of context-specific ecological prototypes that can be validated in relation to a new set of locally and use case specific agricultural/horticultural, architectural, sustainability and ecological performance indicators. The historical case studies provide one of the data-sets that will be incorporated in the ontology. The discussion is concluded with the outline of further research questions and methods.

\section{Materials and Methods}

The research presented in this article builds thus far on two methods, namely literature studies and field surveys. The literature study focuses on selected historical cases of agricultural and horticultural constructions and practices, with the aim to catalogue and analyze these cases with regards to the questions and objectives of this research. The literature study is paralleled by a field survey that serves to fill knowledge gaps or to verify assumptions about the specific functional aspects of the selected case studies.

While some selected case studies are located in hot and arid climates, thus needing to provide shelter from heat and wind and prevent from drying out, others are located in colder climates, thus needing to provide shelter from cold ambient temperatures, frost, etc. For the case-specific field surveys, this entails a detailed understanding of the relation of constructions and practices to the local conditions. Clearly, the historical cases are well embedded in and correlated with their particular settings, unlike many of the generic contemporary cases that rely on technological means to bridge the gap between conditions required by the plants and those provided by the GC.

The aim is to analyze a broad range of case studies that are typical for different climate zones and conditions and to relate these to questions of land use and restoration, and sustainability, as well as climate change, resilience (coping capacity relative to changing conditions) and adaptability (the capacity to enable alteration in response to changing conditions). In this context, climate and micro-climatic data are essential data-sets to be acquired for the purpose of understanding the various functions that these systems have to fulfil and linking these to the conception of new GCs.

In this article, a first related field survey is discussed, which focuses on the micro-climatic effects of the terraced vineyards with dry-stone walls in Tuscay, Italy, that facilitates the growing of high-quality wine at high altitudes. In this case, the field survey serves to validate existing assumptions about the micro-climatic performance of the terraces.

The plan is to conduct field surveys for a broad range of case studies in different contexts and climates, and with different range of ecosystem functions. The undertaken and planned field surveys also serve to refine survey methods and data collection that needs to be adapted to different cases in different contexts. At the same time, they inform the configuration of interdisciplinary research teams for each case-specific set of objectives.

Moreover, the combination between literature study and field survey is thought to deliver the content for analysis and modelling of the information (computational ontology) as a stepping stone to the development of a design decision support system for research on ecological prototypes. This future extension of the work is further elaborated in the discussion section.

The breakdown for the overall projected research is therefore is as follows: 
- Case studies through literature study and comparative analysis. (This will involve historical and contemporary case studies).

- Case studies through field surveys. (This will involve historical and contemporary case studies).

- Case studies through computer simulation and analysis. (This will involve historical and contemporary case studies).

- Configuration of agricultural/horticultural, architectural, sustainability and ecological performance indicators (KPIs) for Ecological Prototypes. (This will involve literature study with the aim to synthesize KPIs from different domains, as well as configuring new ones).

- Configuration of an Information Model (Computational Ontology) that can be reasoned by humans and machines.

- Configuration of a Design Decision Support System.

Thus far, the first two steps are well underway. The following section will examine selected case studies that were analyzed through literature research and, in one case, through field surveys. In the discussion section, further research questions and steps are outlined.

\section{Results}

Attempts at systematizing case studies into an operative taxonomy frequently runs into the problem of ambiguity, with cases fitting into more than one category when viewed from different perspectives. The initial approach for systematizing the case studies this research focuses on, is by way of distinguishing GCs and architectural, agricultural and horticultural designs according to the related types of environmental modification by way of construction and associated practices. In the future, this systematization will be based on functional analysis and case-specific performance indicators. However, the latter will only be possible once a sufficient number of case studies are completed and compared with the aim to develop criteria for defining relevant case-specific KPIs and to inform choices in the acquisition of relevant case-specific data. The way cases are tentatively systematized for the purpose of this article serves only to provide a stepping stone for the argument and research.

The least intrusive systems include forest farming and its most intensive version—forest gardening, as well as ancient methods such as vite maritata that utilizes trees as scaffolds for growing vine [17-19]. The next systems are characterized by modifications of the terrain. Examples are the funnel shaped soil indentations for growing individual vine plants on the Canary island of Lanzarote, the terracing of slopes that can be found in many regions of the world or constructions that support plants in various ways. This includes the use of scaffold-like structures for growing wine, lemon or hop and linear constructions such as dry-stone or masonry walls, or Devon hedges made from earth banks faced with stone or turf with native trees and shrubs growing on it [20]. More elaborate systems include dry-stone walls that often occur in conjunction with terraced landscapes, or as perimeter structures for walled gardens, such as the ones on the Italian island of Pantelleria [21]. Dry-stone or masonry walled gardens can be individual structures or accumulated to extend over large areas, such as the peach gardens in Montreuil near Paris, France, that utilize the so-called fruit walls. These types can either be open to the exterior or include enclosure such as the talut walls. Fully enclosed greenhouses, evolved from the fruit wall with leaning glass surfaces, i.e., talut walls, to 3/4 span greenhouses, observatories, orangeries, hothouses, and to contemporary industrial greenhouses advanced to intensify and sustain production throughout the year. Significant progress in this field emerged through the works of Louden, Paxton and others [22]. These structures can be further distinguished by the degree to which mechanical and electrical means are used to produce an artificial interior climate and of control. However, these latter types are part of another quadrat of the solution space and will be the subject of future case studies.

One hybrid type that is of interest in the context of this research is that of the lemon houses at Lake Garda in Northern Italy, which combine terracing and dry-stone walls with adaptable enclosure that can be opened during the warm season and closed during the cold season. From the list above, 
specific cases are selected for closer examination in this article. These include terraces with dry-stone walls, walled gardens, and lemon houses.

\subsection{Terraces}

Terraced landscapes for agricultural production exist in many regions of the world. Most of them are threatened by land abandonment in many places in spite of their valuable ecosystem services and related intangible land knowledge [23].

Italian terraced landscapes with dry-stone walls are listed in UNESCO's Representative List of Intangible Cultural Heritage of Humanity and Food and Agriculture Organization of the United Nations (FAO) Globally Important Agricultural Heritage Systems (GIAHS). Terraced landscapes can provide a broad scope of ecosystem services and help increase biodiversity [24]. Terracing is a way of stabilizing slopes to prevent landslides and erosion and to gain horizontal ground for planting crops. Depending on the steepness of the slope and the height of the terraces, soil needs to be kept in place by retaining walls that are often made from stone. Commonly, such dry-stone walls are massive for structural reasons and, in result, modulate the micro-climate in their direct vicinity.

The first field survey in this research focuses on terraced landscapes in Lamole, Tuscany, where high-quality red wine is grown at an altitude of about $700 \mathrm{~m}$, by way of terraced vineyards with dry-stone walls. (Figure 2) The collaboration on the survey commenced in 2016 in collaboration with the vineyard owner, Paolo Socci, and researchers from different departments at the University of Florence. At this point, teams from the University of Florence were already working on various questions concerning the terraced vineyards and dry-stone walls [25]. The first stage of the research collaboration lasted from 2016 to 2018 and involved the Research Center for Architecture and Tectonics (RCAT) in Oslo, the Geomatics for Conservation and Communication of Cultural Heritage Laboratory (GECO) at the Department of Civil and Environmental Engineering and the Department of Agricultural, Food and Forestry Systems both at the University of Florence, as well as the Geographical Institute of the Italian Military.

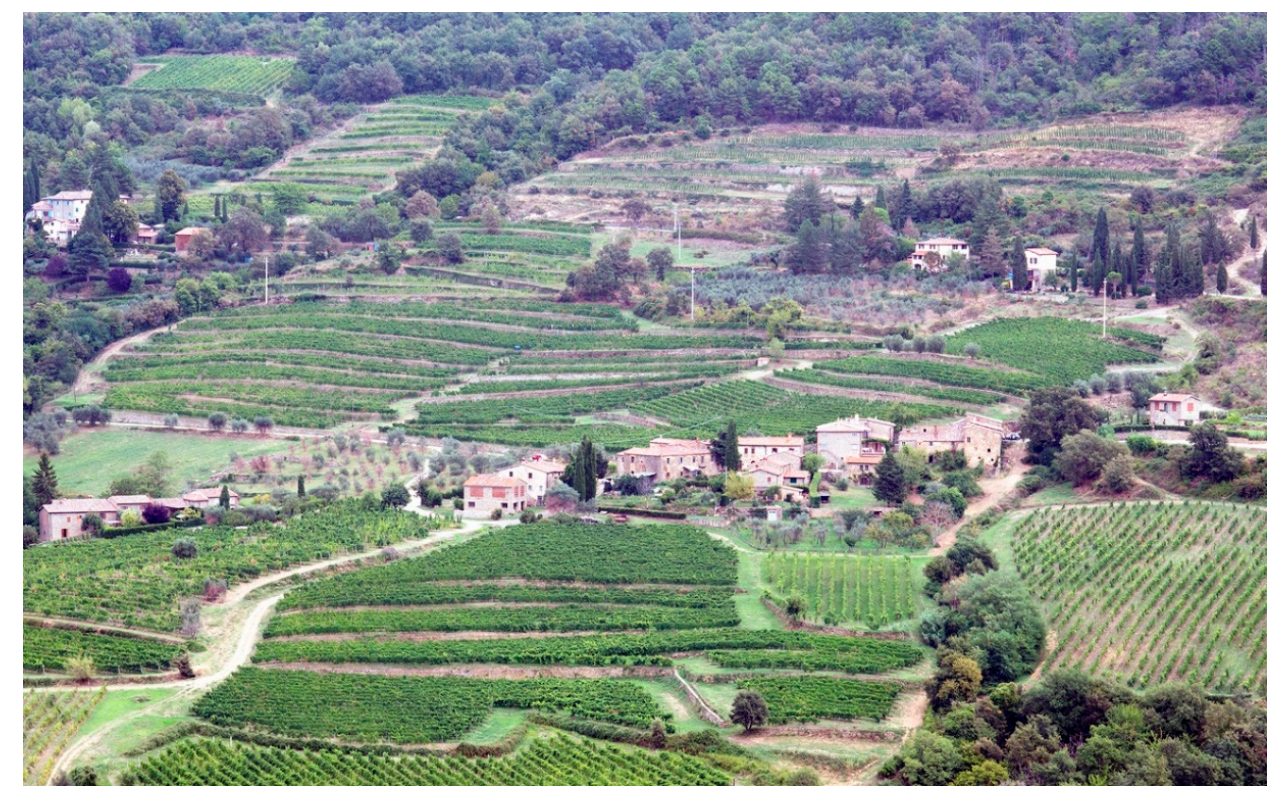

Figure 2. Terraced vineyards with dry-stone walls in Lamole; center: the old Grospoli vineyard; top right: the new Grospoli vineyard.

The research involved multi-modal data-acquisition through unmanned aerial vehicle (UAV)-based surveys (Figure 3) [26] and a network of weather-stations [27]. Our team focused on the survey of the terrace micro-climate. Focus was placed on the influence of the terraces, made of horizontal steps with deep soil and vertical massive dry-stone walls, on the micro-climate. This study was based on the basic 
assumption that the terraces plays an important role in lowering the diurnal temperature variation (DTV) and extending the duration of warmer hours around $20^{\circ} \mathrm{C}$ in the course of the day, in the direct vicinity of the plants. DTV and temperature are two important factors influencing the ripening process and balancing the levels of sugar and acidity in the grape, which contribute to wine quality.

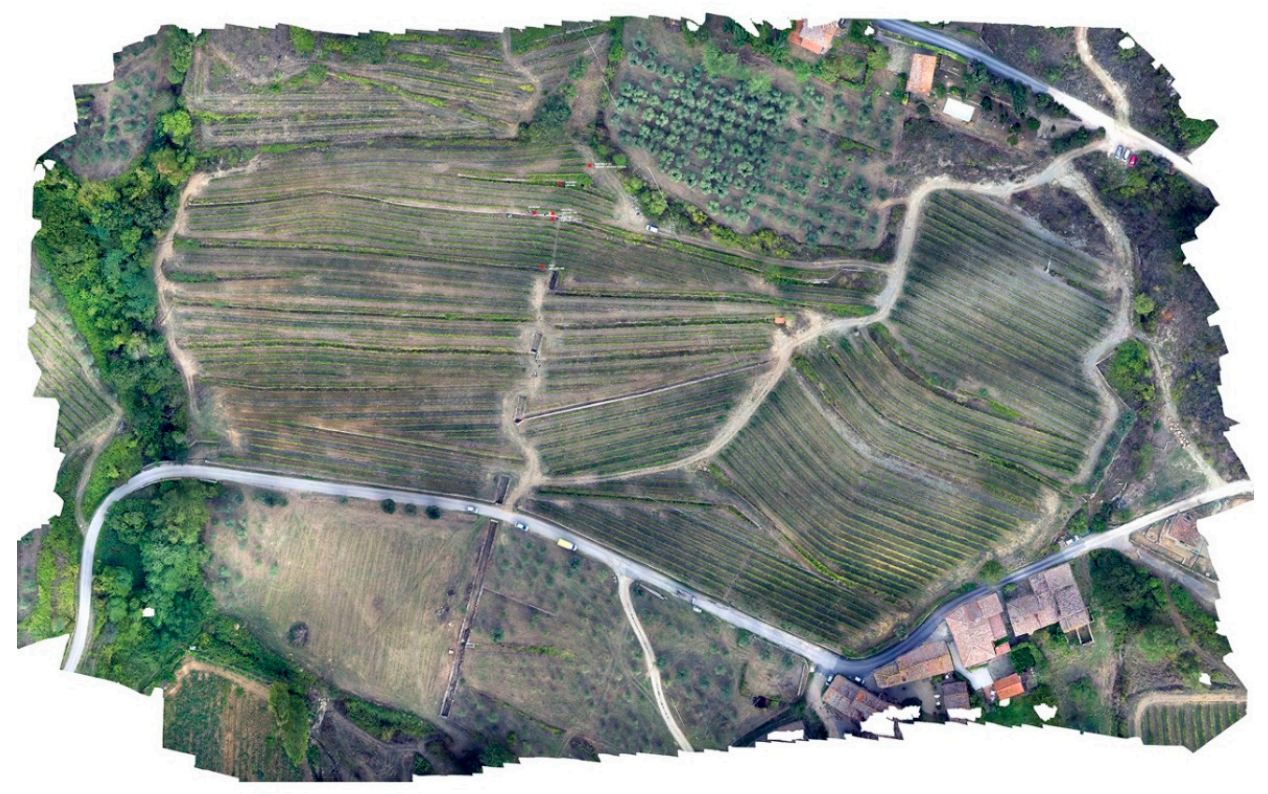

Figure 3. Orthophoto of the old Grospoli vineyard. Orthophoto: Geomatics for Conservation and Communication of Cultural Heritage Laboratory (GECO), 2016.

Initially five weather-stations were installed on two terraces for the duration of two years. (Figure 4) The stations were equipped with sensors for ambient and soil temperature and humidity, precipitation, wind direction and velocity, and the stations were placed on two terraces at different distances from the dry-stone walls. One station was placed on a nearby slope without terraces to obtain data for comparison. The data from the stations were transmitted to a central station that could be remote-accessed. Due to the weak Wi-Fi signal, some data losses occurred and prevented the acquisition of a full annual cycle of measurements. However, sufficient data were acquired during the relevant months for vine growing to observe the effects on air temperature.

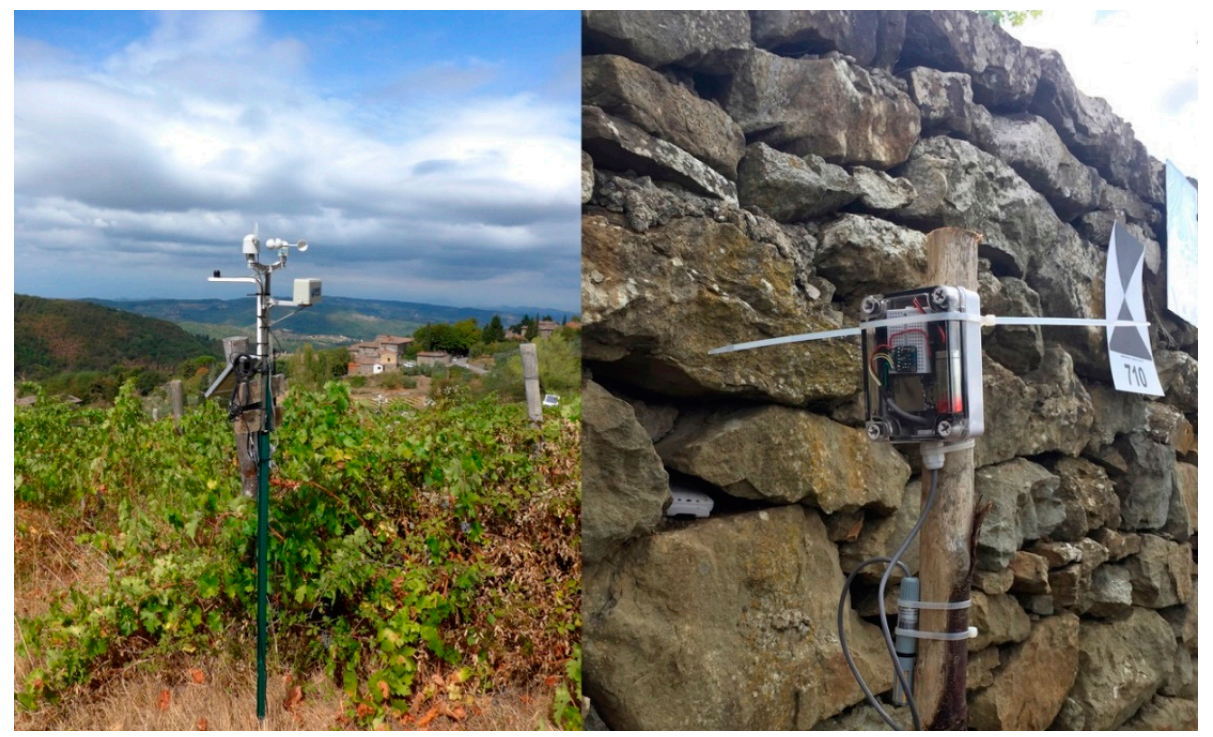

Figure 4. Weather-stations on the old Grospoli vineyard. Photography: Michael Hensel, 2017. 
In order to corroborate the findings, a second series of surveys commenced in 2019 that involved the department for Digital Architecture and Planning (DAP) at the Vienna University of Technology, the Geomatics for Conservation and Communication of Cultural Heritage Laboratory (GECO) at the Department of Civil and Environmental Engineering at the University of Florence and the Chair for Building Technology and Climate Responsive Design at the Technical University in Munich. These surveys will run until 2023 and the interdisciplinary team will focus on a multi-scalar approach, in which data is acquired through UAV-based survey to generate point-clouds of the terrain and thermography, (Figure 5) again correlated with terrestrial measurements of ambient temperature and other micro-climatic data.

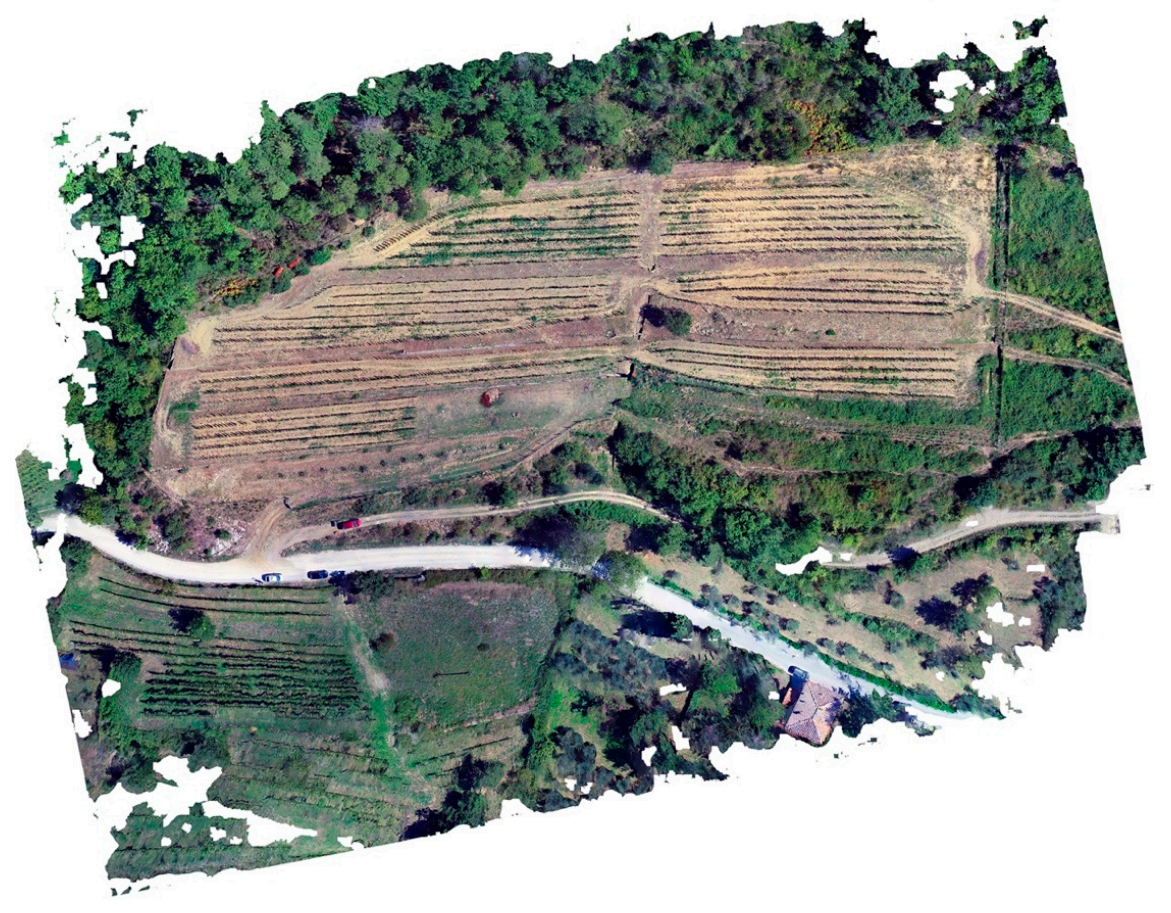

Figure 5. Orthophoto of the new Grospoli vineyard. Orthophoto: GECO, 2019.

The 2019 thermographic survey shows the surface temperature of the dry-stone walls from 8:00 a.m. to 22:30 p.m. Sunset occurred at 19:30 p.m. and the walls remain thermally active after that time (Figure 6).

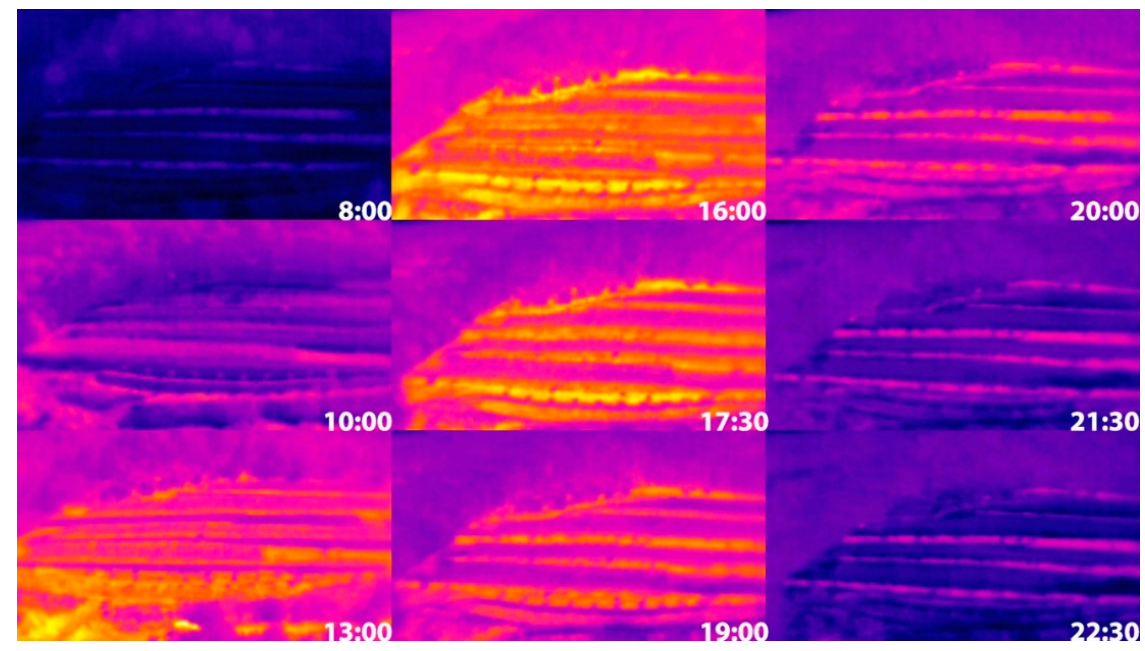

Figure 6. Timeline of thermography of the new Grospoli vineyard. Thermography: Digital Architecture and Planning (DAP), 2019. 
The research also showed that depending on the orientation, the soil of the terraces begins to be thermally active before the dry-stone walls. (Figure 7) This occurs on the vineyards with orientation to the west, where the dry-stone walls remain in shadow until the late morning. The thermal performance of the soil implies that the ambient temperature on the terraces during the earlier hours of the day raises faster to the desirable temperature range around $20^{\circ} \mathrm{C}$.

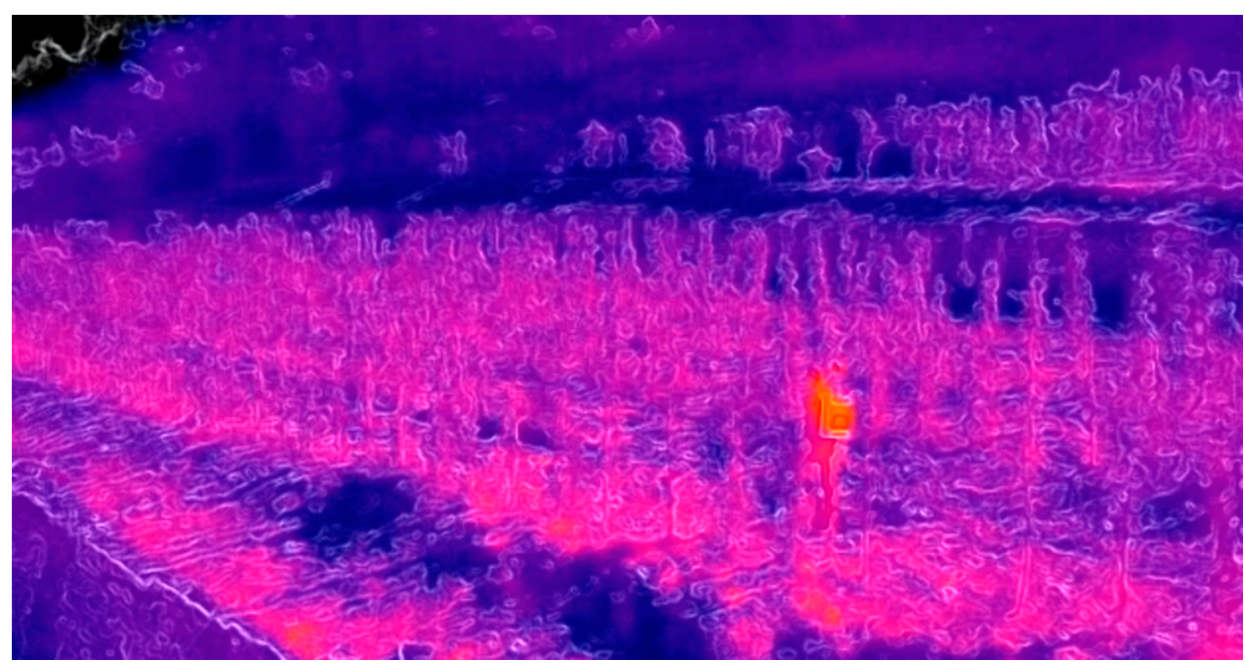

Figure 7. Frame of a thermographic video. Thermography: DAP, 2019.

The field surveys will continue over the next four years involving a multi-scale approach, from the scale of the individual plant to the micro-climate and topo-climate scales. This will be done with the aim to better assess the correlation between thermal performance of the horizontal stepped soil and dry-stone walls in relation to the topo-climate, as well as the impact on the plant scale.

Furthermore, these field surveys serve the purpose of establishing strategy, methods and technologies that will be used for the detailed analyses of other case studies. This research collaboration has also led to the inception of the LamoLab Research Center located in Lamole, with the aim to conduct surveys all year round and on a variety of case studies.

\subsection{Walled Gardens}

Gardens are, by definition, enclosed by plants or hedges, fences or constructions. Throughout human history enclosure was a means to protect and deliver special attention to plants [28], thus enabling nuanced orchestration of location-specific relations between construction, micro-climate and species. In this context, dry-stone or masonry walls were used in highly sophisticated ways.

The landscape of the Italian island of Pantelleria is characterized by ancient agricultural practices and constructions that have led to high biocultural diversity [29]. Approximately $80 \%$ of the island's landscape is characterized by terracing and dry-stone walls, with the latter either in conjunction with terracing, or as fencing, or defining elements of special spatial structures such as the walled gardens. (Figure 8) The climate of Pantelleria is semi-arid with long dry and hot seasons and strong winds. Due to lack of natural freshwater sources and little rainfall, the water deficit is high. Water harvesting is essential and there exists a large number of historical cisterns in which rainwater is collected. The agricultural landscape and the constructions that are part of it are determined by these local climatic conditions of high summer temperatures and intense winds. Dry-stone walls provide sheltering from the wind and are linked with practices of plant pruning and training toward low growth to protect plants. A distinct feature of Pantelleria are the walled gardens, the giardini panteschi. These are characterized by a high dry-stone wall that encircles a single citrus tree that cannot be pruned without considerable loss of yield. The wall supports the tree by offering protection from the wind, balancing diurnal temperature variation, reducing evapotranspiration, securing water availability 
through dew collection and condensation [30]. Guiseppe Barbera pointed out that "this contribution of water is so important that it allows citruses to be cultivated in the total absence of irrigation" [31]. The collection of non-rainfall water employed by the giardini panteschi belongs to the broad range of strategies and constructions that evolved from coping with the desertification of the Mediterranean [32]. These strategies are contrasted with the approaches in places where water is more abundant, for instance in the example of the lemon houses at Lake Garda.

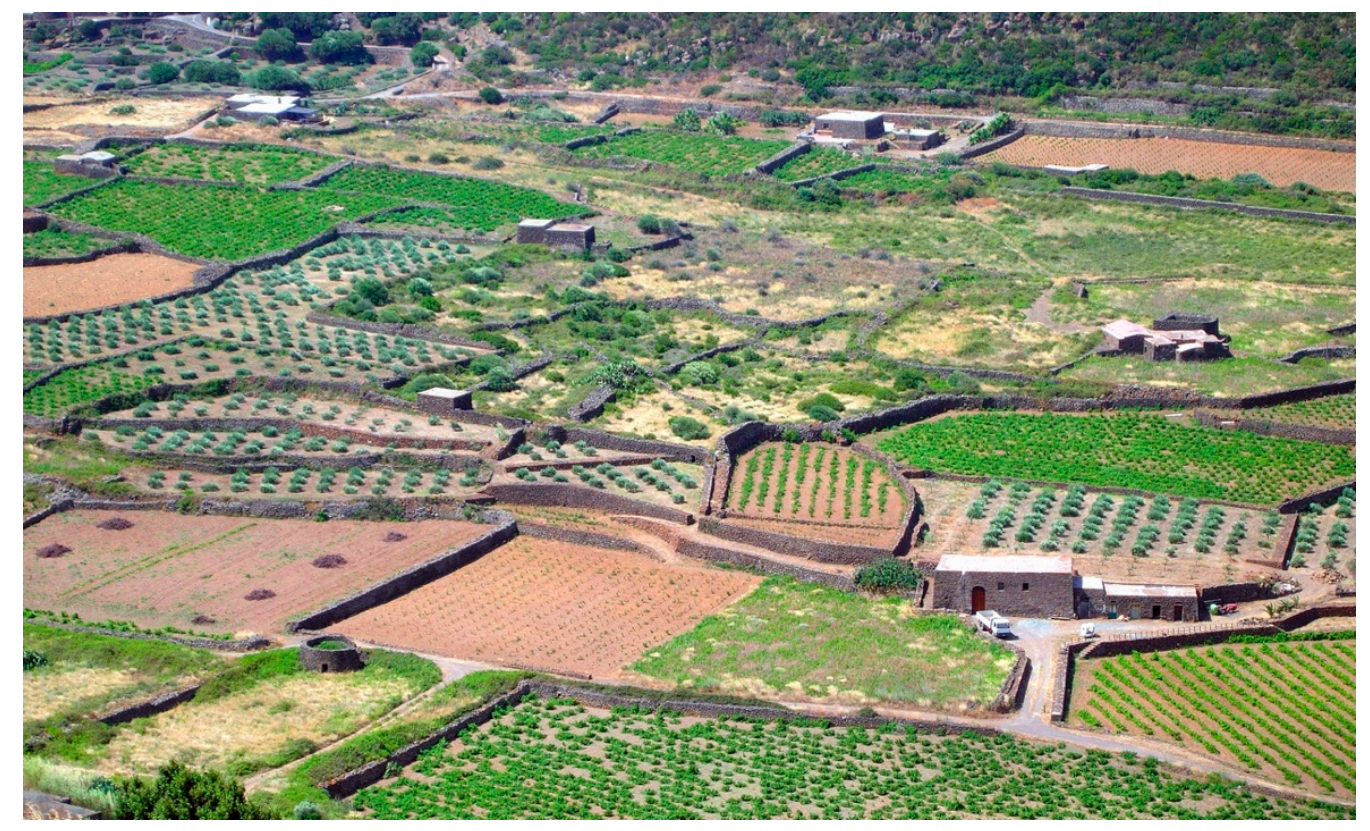

Figure 8. The typical landscape of Pantelleria. Photography: Luca Volpi, 2007.

The variation seen in the walled garden typology is linked with the variation in climatic conditions in different geographic locations. Countries like the Great Britain and France have a rich history of building walled garden types in different sizes, from small gardens to large mansion gardens [33].

Related to the development of the walled garden, is that of the actual wall and its micro-climatic performance. This led to the emergence of the so-called fruit wall during the little ice age from the 16th to the 19th century, when it was necessary to provide the required conditions for growing fruit plants in temperate regions. Two Swiss polymaths contributed to the development of the modern fruit wall. Conrad Gessner (1516-1565) explained the effect of sun-heated walls on growing different plants, and Nicolas Fatio de Duilier (1664-1753) wrote a treatise on how to improve fruit walls to increase yield [34]. (Figure 9) A broad range of fruit walls were developed together with specific pruning techniques. This led to the development of the espalier, trees and shrubs with branches trained to grow flat along a masonry wall and often supported by wooden lattices. One development is the so-called Talut wall, which features a small cantilevering roof to protect the espalier. For further protection, sheets of glass were mounted in front of the plants. Talut walls can still be found in some places, such as the vineyard Krapenberg in Radebeul, and in the garden of palaces such as Sanssouci in Potsdam and Herrenhausen in Hannover.

The so-called hot walls that emerged in Great Britain embedded heating in the wall through a system of chimneys and flues and even hot-water pipes. This made it possible to keep temperatures high enough in the winter to protect the plants from cold and frost, and to provide continual heat for those species that required it [35]. Together with the strategy of leaning sheets of glass against fruit walls, to increase their thermal effect, the heated walls marked a departure towards energy-based solutions and full enclosure that led to the development of the modern glass greenhouse. 


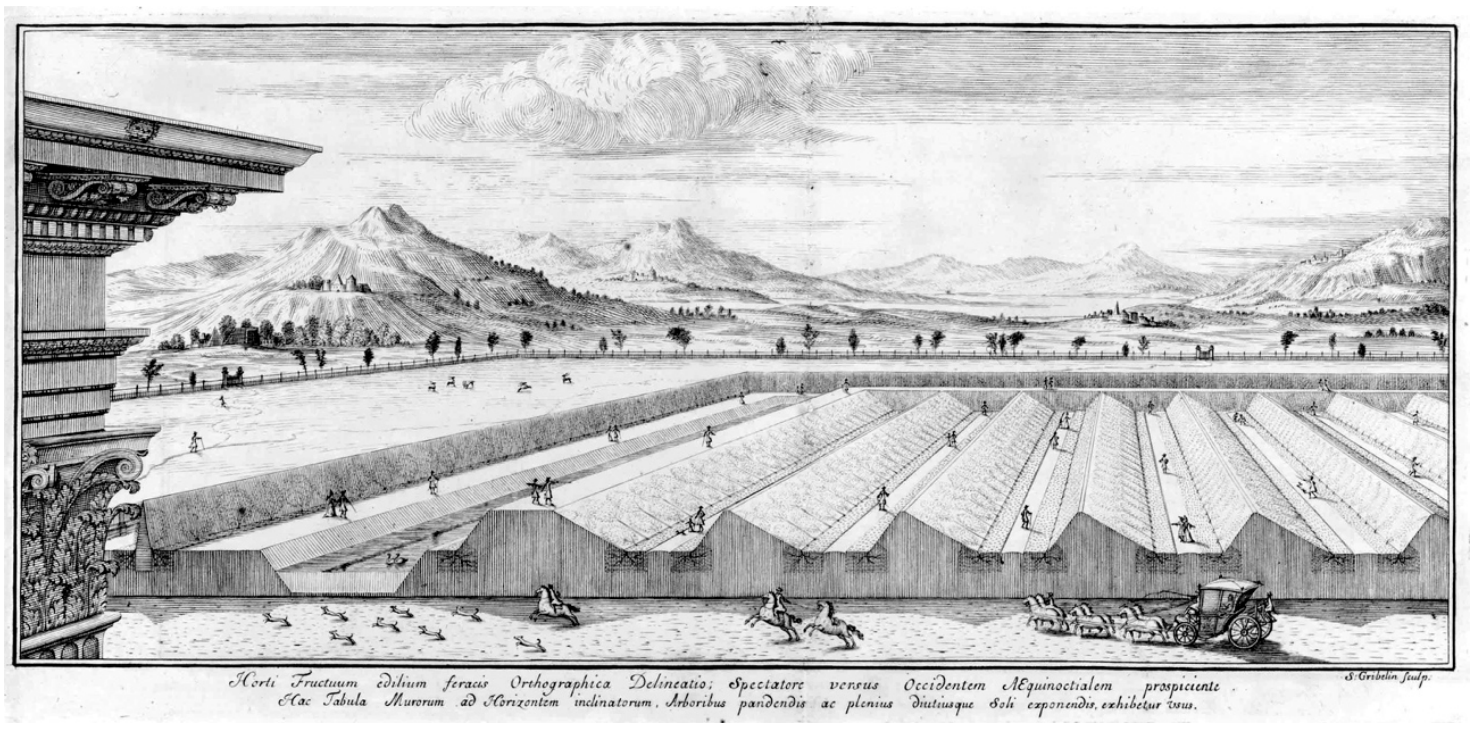

Figure 9. Engraving from Fatio de Duiller's Fruit-Walls Improved, By Inclining them to the Horizon: or, a way to build walls for fruit-trees. R. Everingham: London, UK, 1699.

There exists extensive applications of fruit walls over large areas. One striking example are the walls for vine cultivation in Thomery, near Paris in France, with its unique system of training vine upon trellises [36]. This method of cultivation served to overcome disadvantageous orientation and poor soil conditions. Full South orientation for maximum solar gain was not possible as the plants required protection from damp southerly winds. At the height of vine production in Thomery in the 1920s, there existed ca. $350 \mathrm{~km}$ of walls against which the vine plants were trained. The walls were ca. $3 \mathrm{~m}$ tall and up to $100 \mathrm{~m}$ long, running parallel at a distance of ca. $9 \mathrm{~m}$. Vines were only grown on the side of the wall that enjoyed solar exposure. The Thomery method and quality of wine was reported by the New England Farmer and Horticultural Journal in 1828 and by John Phin in his 1862 book on "Open Air Grape Culture" [37].

Another example of large-scale applications of walled gardens are the peach orchards of Montreuil with their mur à pêches (peach walls). In 1907, the peach walls covered an area of ca. 300 hectares [38]. Abbé Jean-Roger Schabol described the peach orchards in a text dating from 1755 [39]. Apparently, the walls first emerged to demarcate plots and garden. It soon showed, however, that the micro-climatic impact of the walls on growing peaches was advantageous and the method was swiftly perfected with walls oriented along east-west direction, to utilize south exposure. These open-air peach walls captured, retained and released the sun's heat to the benefit of cultivating early and late fruit varieties. They did so by creating a micro-climate close to the walls that is approx. 10 degrees centigrade higher than its surrounding.

As mentioned above, this type of walled garden and the fruit wall were developed out of the necessity to improve micro-climate during the cold spell of the little ice age from the 16th to the 19th century. With global climate change unfolding, the question arises as to how to adapt the knowledge gained from these and other cases to changing conditions and needs. Some walled gardens, such as the giardini panteschi of Pantelleria, are more directly suited to offer insight and strategy for hot and dry contexts. At any rate, it is of interest to organize the broad range of walled gardens and fruit walls in accordance with their specific climatic context, and thermal and micro-climatic functions. For this, it will be necessary to acquire further data on their specific performances.

\subsection{Lemon Houses}

The lemon houses (limonaie) at Lake Garda enable the cultivation of lemon trees in a climate that is not optimally suited for the purpose (Figure 10). 

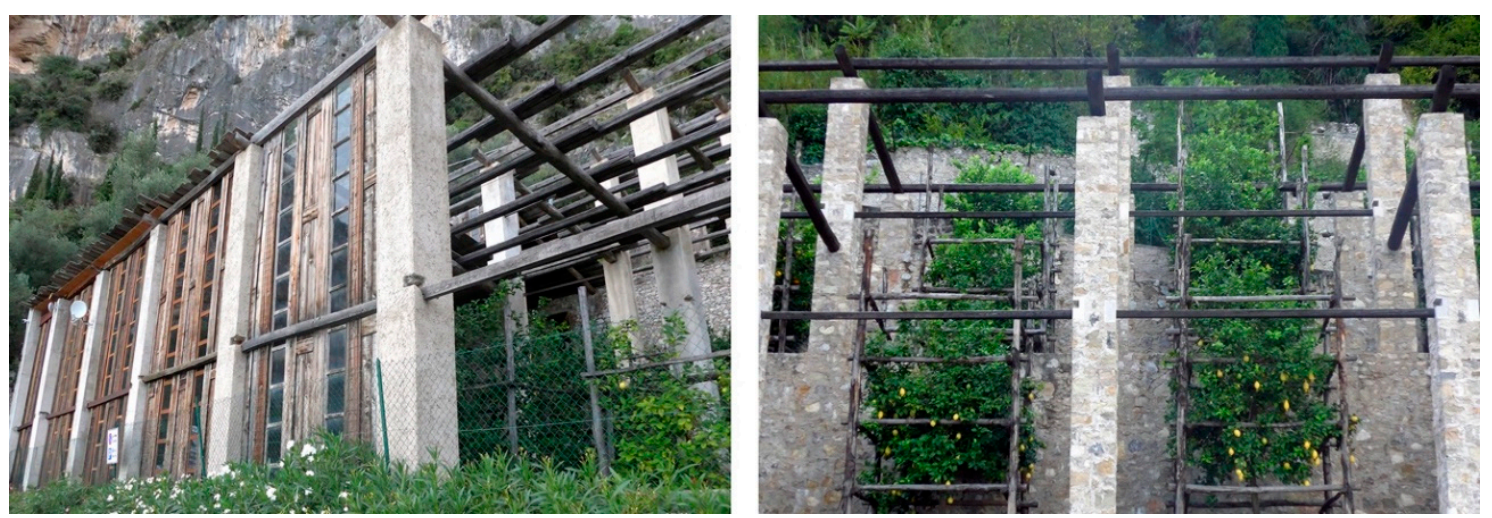

Figure 10. Lemon houses at Lake Garda; left: partly enclosed and partly open structure; right: lemon trees with scaffolding. Photography: Defne Sunguroğlu Hensel, 2019.

The lemon houses are built on the steep slopes on the west side of Lake Garda with an orientation towards South- to North-East, taking advantage of existing water courses, the particular mild climate due to the presence of a large water body and the areas protected by the mountains from the cold winds. It is this unique type of construction that makes it possible to grow citrus, a species native to South Asia-primarily North eastern India, this far North at a latitude of 45 Degrees. The first lemon house built by the Bettoni family at the end of the 18th century marked the start of a particular local tradition of lemon farming [40].

One key feature is the conversion of a steep slope into a terraced landscape. The terraces have massive stone walls on three sides with the fourth side open to provide solar exposure. The trees were grown to reach 8 to $9 \mathrm{~m}$ in height to increase yield. Wooden scaffolds provide support for the trees that lay shallow and horizontal roots. A grid of ca. $10 \mathrm{~m}$ tall square pillars support a wooden roof and movable walls made from wood and glass. The roof and walls are removed during the warm season and added during the cold season. There are additional buildings for storing the movable building parts during the warm season, and frequently, the farmers' houses were also integrated in this ensemble.

In contrast to the non-irrigated walled garden system of Pantelleria, the lemon house system of citrus cultivation at Lake Garda in Italy depended on the presence of water sources and a sophisticated irrigation network for the supply, distribution, discharge and drainage of water. Water management is essential to provide enough water for the trees, amounting to 150 to $300 \mathrm{~L}$ every ten days during the summer period [41]. The terraces enabled the distribution of the water taken from an uphill reservoir or streams through flumes and spillways to deliver water to the roots of each individual tree.

Steep slopes are particularly prone to landslides, water runoff, and other hydrological hazards. Through its stonewalls and terraced terrain form, the lemon-houses help stabilize and protect the soil from erosion, direct the necessary amount of water to where it is needed, and together with the thermal mass of the walls and soil help store solar heat gained during the day to extent the required temperature into the night. Land abandonment and inconsiderate urban planning has diminished the use of this type and its associated provisioning, regulating and cultural ecosystem services. However, there are concerted efforts for revitalizing this traditional land knowledge, and conservation and reactivation of these historical agricultural systems. It was suggested that "a deeper knowledge of all the possible immaterial benefits of Lake Garde lemon houses might help overcome the limits of Urban Planning and to find a way to reuse lemon houses for more affordable and competitive functions than the investment in real estate" [42].

Another version of these are the terraced lemon orchards in the Amalfi coast, in the south of Italy, that feature a temporary retractable cover with black and green nets. In the context of Amalfi, this is sufficient enough to protect the trees in winter. 
The lemon-house of Lake Garda expresses an interesting transition from open to adaptable types of construction and to greenhouses. Since there are only a few sources of information that document knowledge about these agricultural systems and how they were operated, it is important to conduct detailed surveys and analysis to gather data about how they make citrus farming possible in this climate.

\section{Discussion}

The case studies discussed above, and further planned case studies, can be grouped according to specific climate responses. Some case studies are located in hot and arid climates, thus needing to provide the plants shelter from heat and wind and prevent from drying out. These include the walled gardens and terraces for hot and arid climates. Some case studies are located in colder climates, thus needing to provide shelter from cold wind and temperature, frost and eliminate high temperature fluctuations etc. These include fruit walls, talut walls, walled gardens for colder climates, the lemon houses at Lake Garda, orangeries, etc. These cases are invariably and quiet obviously well planned in relation to, and coupled with, their contexts unlike the generic and decoupled contemporary types that frequently rely on technological means to bridge the gap between what plants need and those provided by the GC.

While this seems obvious, the knowledge related to the design and operation of these historical systems of agriculture and horticulture has not been well recorded, largely been lost or is at risk of being lost in the near future. One of the aims of this research is to learn from these examples and recover this knowledge for adaptation to changing contemporary environmental needs, goals and circumstances. This involves gaining a better understanding of the various solutions to problems that have been developed and accumulated over generations, and to compare them with today's specific requirements and conditions to identify design gaps and potentials for transfer. The data that are needed to perform functional analysis and validation of theoretical results is mostly missing, for instance local climatic data. In the case of the terraces in Lamole, a long-term surveying effort commenced in 2016 has already provided relevant insights and data. However, current climatic conditions frequently do not resemble the climatic conditions of the past, which the specific cases were developed for. This is, for instance, evidenced by the wealth of constructions that evolved in the colder parts of Europe during the little ice age. In order to understand and compare past and present conditions, it will be necessary to not only collect data on site, but to undertake computer simulations based on recorded past conditions, and compare them with how they are configured and perform today. This will support an understanding of the resilience or need for adaptation of each case in the current climatic context. Based on the data acquired from surveys and computer simulations, the adaptability of these systems can be evaluated. Historical design strategies and practices in response to climate change can be recorded and adapted to current situations. In the context of Lamole, for instance, vine farmers move their production further uphill to higher elevations and change the main direction of solar exposure in response to climate change. This can indicate the need for developing, for example, spatial strategies and modifying surface orientation and proximity to construction in peri-urban and urban contexts to enable food production and ecosystems to adapt to changing climatic conditions to a necessary extent. This may, however, come into conflict with current land use types and allocations as discussed further below.

In order to enable the design of ecological prototypes, a methodological framework needs to be in place. The emerging research agenda necessitates a large number of case studies, and related field surveys to acquire and utilize this information and knowledge obtained from functional analyses and literature surveys. This data will need to be collected and structured, and related information and knowledge will need to be modelled and integrated with the already existing information, to generate a design search space that is dynamically configured based on query and key performance indicators that help locate GC solutions in the design space. An indicator can be understood as, "a measure based on verifiable data that conveys information about more than itself", meaning that indicators 
are purpose-dependent, and selected according to the decision-making needs that they address [43]. Developing a framework for identifying case-specific indicators for GC is a complex interdisciplinary problem. The quality of subsequent analysis of synergies and trade-offs for each specific ecological prototype designs will depend on the particular choices of KPIs. There exist proposed models for evaluating synergies and trade-offs for ecosystems services [44] and for GI [45] and urban agriculture [9], i.e., for vertical farming [46]. However, these are either not directly applicable to the design and assessment of ecological prototypes, or not correlated with other indicators, as will be required for characterizing, developing and evaluating this particular region of the GC design space.

Data derived from GC case studies will feed into and inform an information model ontology (knowledge-base) to facilitate data-driven design decision support for GC. (Figure 11) The case studies adopt a functional approach, where selected systems of study are analyzed from a multi-scale and multi-criteria perspective to comprehend and capture systemic relations, facilitated by the information model. This makes it possible to configure the design space dynamically according to query and corresponding case-specific performance indicators. The case study data will constantly evolve and be updated, and will be integrated with other data-sets in the ontology. In the long term full-scale context-specific prototypes will need to be realized in order to validate the new GCs that are developed through the utilization of the information model and decision support system.

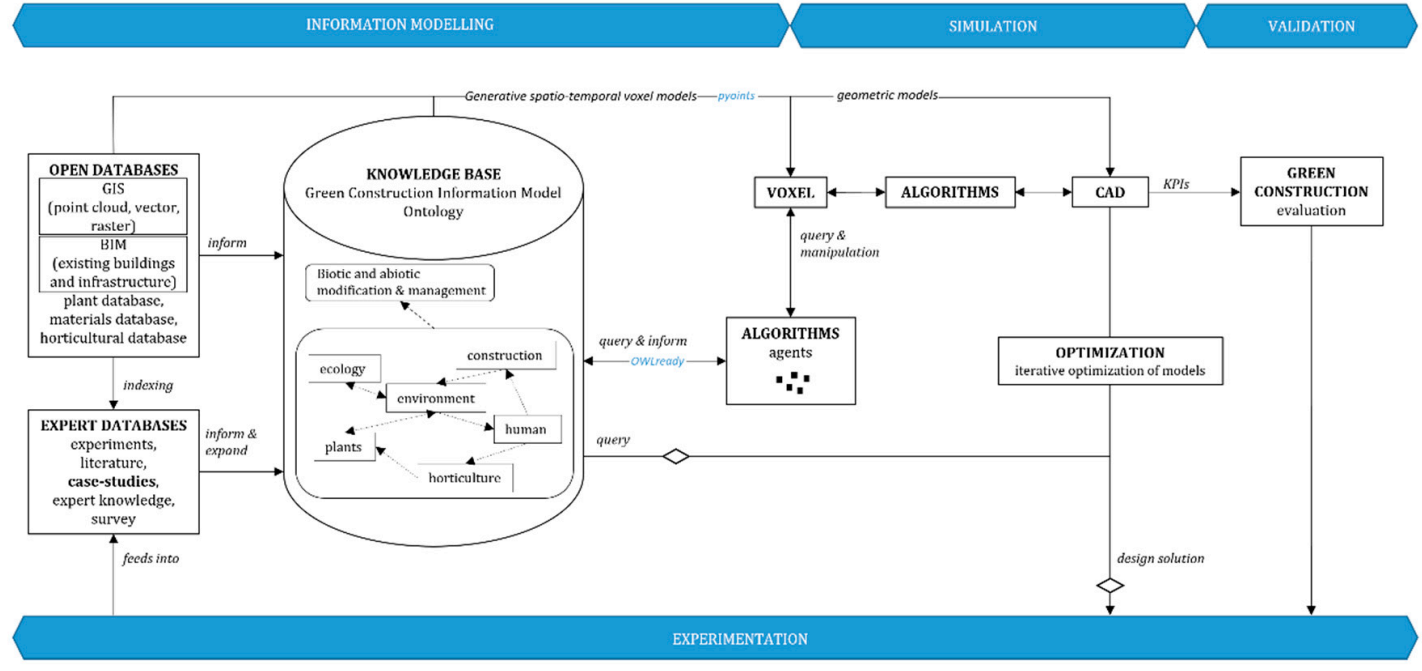

Figure 11. Workflow diagram showing the main components of the decision support system for designing ecological prototypes, connecting database, ontology, and optimization. Defne Sunguroğlu Hensel, 2020.

The aim of the GC information model ontology is to bring environmental intelligence into computational data-driven design. The information model is an important component of the proposed data-driven design decision support system. It enables capturing, integrating, manipulating, discovering data and translating it into actionable information for design. This is aided by computational ontology (Artificial Intelligence and Knowledge Engineering) and machine reasoning. The ontology will be developed to facilitate exploring the GC design space, and to discover and generate new possible designs that will re-configure and expand the problem-solution space. This entails a multi-scale (spatial and temporal scales) and multi-perspective (functions) design space, which can be queried both by human and machine agents. The information model will be the basis to generate and manipulate the intensification-restoration chart. Each query will dynamically modify the graph for each data point to inform an iterative and recursive problem-definition and problem-solving process, creating a robust and reliable basis for design generation, optimization and evaluation. Subsequently, the GC information model will be linked with an intensification-restoration assessment method, combined 
with a related plant selection method to generate design feedback. This will enable a new workflow for the design of ecological prototypes. (Figure 11)

One of the anticipated questions that ecological prototypes will likely to raise is the question of land use, i.e., the transformation of natural environment or arable land into built environment and related allocations of land use types. Recent research on the relation between nature, biodiversity, ecosystem services, and human health and well-being is pointing in similar directions, namely that re-envisioning land-use planning and related policy development from an interdisciplinary perspective will be needed [4].

Ecological prototypes research is likely to challenge the existing land use types by treating construction, agriculture/horticulture and architecture, as well as ecosystem and biodiversity as a hybrid system that may currently be seen as contradictory and mutually exclusive from today's land use perspective. This can be addressed in multiple ways, i.e., simply by continuing the greening of cities and architectures based on land use assigned for construction. While this may well work to some extent, this solution tends to prioritize one type, while treating other components as add-ons. In order to go beyond this approach, it will be useful to consider new hybrid land use types that consider construction, agriculture, architecture and nature preservation and restoration on equal footing with the aim to ensure a balanced outcome of different trade-offs. Furthermore, this could lead to new ways of developing areas over time in which a new balance between nature protection, food production and construction is successively derived. Hybrid architectural typologies need to be in place to enable this process. It is the aim of the ecological prototypes research to provide these hybrid typologies. Furthermore, in terms of the hybrid nature of this new type of GC, it is of interest to consider which combination of sustainable development goals [47] can be addressed in each location specific design of ecological prototypes, essentially acknowledging the compound nature of sustainability problems [48]. This involves linking detailed requirements of meeting joint sustainability goals with KPIs of ecosystems and urban ecosystems.

\section{Conclusions}

This article initiates a new approach to Green Construction (GC) entitled ecological prototypes, conceived of as integrated and adaptive systems of design, construction and practices that link architecture, horticulture and agriculture, landscape and ecology. The aim is to expand the design space for GC. Ecological prototypes seek to reconcile different environmental needs and goals, balance intensification and restoration trade-offs and support ecosystems and the delivery of ecosystem services especially in degraded peri-urban and urban contexts.

In order to commence this research and build towards insights, strategy and methods, an analysis of selected historical agricultural systems was started. These case studies inform future research on the development of ecological prototypes and aid their design. The analysis of case studies needs to continue taking different contexts and climates into consideration, while building a system within which they can be decomposed, characterized, correlated and classified.

In the following research phase, a systematic approach will be organized around key performance indicators that are obtained and synthesized from different related domains and new KPIs will be formulated. In this endeavor, the development and integration of relevant multi-scale computational methods and tools for data-driven discovery and system development, and context-specific decision-making are key aspects of future research. The role of information modelling and data-driven computational methods in designing ecological prototypes is discussed as a next step in the research, while continuing to systematically analyze and broaden the scope of case studies. At the core of this research is the development of a decision support system to enable the design of ecological prototypes for GC that do not currently exist but are needed to address some of the most pressing environmental challenges of our time. 
Funding: This research received no external funding.

Acknowledgments: My sincere gratitude goes to my collaborators at the Department of Digital Architecture and Planning at Vienna University of Technology, especially Michael Hensel, Senior Lecturer Arnold Faller and Jakub Tyc; at the Geomatics for Environment and Conservation of Cultural Heritage Laboratory at the University of Florence, especially Grazia Tucci and Erica Parisi; at the Chair of Building Technology and Climate Responsive Design, especially Thomas Auer, Daniele Santucci and Ata Chokhachian; and to Paolo Socci, proprietor of Fattoria di Lamole.

Conflicts of Interest: The author declares no conflict of interest.

\section{References}

1. Groffman, P.; Avolio, M.; Cavender-Bares, J.; Bettez, N.D.; Grove, M.J.; Hall, S.J.; Hobbie, S.E.; Larson, K.L.; Lerman, S.B.; Locke, D.H.; et al. Ecological homogenization of residential macrosystems. Nat. Ecol. Evol. 2017, 1, 0191. [CrossRef] [PubMed]

2. McDonald, R.I.; Mansur, A.V.; Ascensão, F.; Colbert, M.; Crossman, K.; Elmqvist, T.; Gonzales, A.; Güneralp, B.; Haase, D.; Hamann, M.; et al. Research gaps in knowledge of the impact of urban growth on biodiversity. Nat. Sustain. 2020, 3, 16-24. [CrossRef]

3. Maes, J.; Teller, A.; Erhard, M.; Grizetti, B.; Barredo, J.I.; Parachini, M.L.; Condé, S.; Somma, F.; Orgiazzi, A.; Jones, A.; et al. Mapping and Assessment of Ecosystems and Their Services-An Analytical Framework for Mapping and Assessment of Ecosystem Condition in EU 2018. Available online: https://ec.europa. eu/environment/nature/knowledge/ecosystem_assessment/pdf/5th\%20MAES\%20report.pdf (accessed on 25 June 2020).

4. Sandifer, P.A.; Sutton-Grier, A.E.; Ward, B.P. Exploring connections among nature, biodiversity, ecosystem services, and human health and well-being: Opportunities to enhance health and biodiversity conservation. Ecosyst. Serv. 2015, 12, 1-15. [CrossRef]

5. Douglas, I. Urban ecology and urban ecosystems: Understanding the links to human health and well-being. Curr. Opin. Environ. Sustain. 2012, 4, 385-392. [CrossRef]

6. EEA-The European Environment-State and Outlook 2015. Available online: https://www.eea.europa.eu/ soer-2015/global/action-download-pdf/file (accessed on 22 April 2020).

7. European Commission. Building a Green Infrastructure for Europe; Publications Office of the European Union: Luxembourg, 2013.

8. UN Environment International Resource Panel—Land Restoration for Achieving the Sustainable Development Goals. Available online: https://wedocs.unep.org/bitstream/handle/20.500.11822/29749/LandSDG.pdf? sequence $=1 \&$ is Allowed $=y$ (accessed on 22 April 2020).

9. Artmann, M.; Sartison, K. The role of urban agriculture as a nature-based solution: A review for developing a systemic assessment framework. Sustainability 2018, 10, 1937. [CrossRef]

10. Dover, J. Green Infrastructure-Incorporating Plants and Enhancing Biodiversity in Buildings and Urban Environments; Routledge: London, UK; New York, NY, USA, 2015.

11. Lyytimäki, J. Indoor ecosystem services: Bringing ecology and people together. Hum. Ecol. 2012, 19, 70-76.

12. Mayrand, F.; Clergeau, P. Green Roofs and Green Walls for Biodiversity Conservation: A Contribution to Urban Connectivity? Sustainability 2018, 10, 985. [CrossRef]

13. Salvatore Pasta, N.M. The Alien vascular Flora of Linosa (Pelagie Islands, Strait of Sicily): Update and management proposals. Willdenowia 2017, 47, 135-144. [CrossRef]

14. La Mantia, T.; Carimi, F.; Di Lorenzo, R.; Pasta, S. The Agricultural Heritage of Lampedusa (Pelagie Archipelago, South Italy) and its key role for cultivar and wildlife conservation. Ital. J. Agron. 2011, 6, 106-110. [CrossRef]

15. Hensel, M.; Sunguroğlu Hensel, D. Embedded Architectures: An Overarching Approach to Compund Sustainability Problems including Urban Climate Mitigation. In Activating Public Space-An Approach for Climate Change Mitigation; Battisti, A., Santucci, D., Eds.; Technical University Munich: Munich, Germany, 2020; pp. 55-64.

16. Sunguroğlu Hensel, D.; Vincent, J.F.V. Evolutionary inventive problem solving in biology and architecture: ArchiTRIZ and Material-Ontology. Intell. Build. Int. 2015, 8, 118-137. [CrossRef]

17. Smith, J.R. Tree Crops: A Permanent Agriculture; Devin-Adair: New York, NY, USA, 1950. 
18. Molnar, T.J.; Kahn, P.C.; Ford, T.M.; Funk, C.J. Tree Crops, a Permanent Agriculture: Concepts from the Past for a Sustainable Future. Resources 2013, 2, 457-488. [CrossRef]

19. Buono, R.; Vallariello, G. La vite maritata in Campania. Delpinoa 2002, 44, 53-63.

20. Wolton, R.; Pollard, K.; Goodwin, A.; Norton, L. Regulatory services delivered by hedges: The evidence base. In Report of Defra Project LM0106; Hedgelink: Defra, UK, 2014; pp. 1-99.

21. Lommatzsch, I.; Brignone, F. Die Jardini von Pantelleria. ICOMOS Hefte Dtsch. Natl. Orangerien Eur. 2007, 43, $86-90$.

22. Hix, J. The Glasshouse; Phaidon: London, UK; New York, NY, USA, 1996.

23. Varotto, M.; Bonardi, L.; Tarolli, P. (Eds.) World Terraced Landscapes: History, Environment, Quality of Life; Springer Nature: Cham, Switzerland, 2019.

24. Socci, P.; Errico, A.; Castelli, G.; Penna, D.; Preti, F. Terracing: From Agriculture to Multiple Ecosystem Services. In Oxford Research Encyclopedia on Agriculture; 2009; In Press; Available online: https:/oxfordre.com/environmentalscience/view/10.1093/acrefore/9780199389414.001.0001/ acrefore-9780199389414-e-206 (accessed on 11 May 2020).

25. Preti, F.; Guastini, E.; Penna, D.; Dani, A.; Cassiani, G.; Boaga, J.; Deiana, R.; Romano, N.; Nasta, P.; Palladino, M.; et al. Conceptualization of Water Flow Pathways in Agricultural Terraced Landscapes. Land Degrad. Dev. 2018, 29, 651-662. [CrossRef]

26. Tucci, G.; Parisi, E.I.; Castelli, G.; Errico, A.; Corongui, M.; Sona, G.; Viviani, E.; Brescri, E.; Preti, F. Multi-Sensor UAV Application for Thermal Analysis on a Dry-Stone Terraced Vineyard in Rural Tuscany Landscape. ISPRS Int. J. Geo-Inf. 2019, 8, 87. [CrossRef]

27. Hensel, M.; Sunguroğlu Hensel, D.; Sørensen, S. Embedded Architectures: Inquires into Architectures, Diffuse Heritage and Natural Environments in Search for better informed Design Approaches to Sustainability. Time Archit. 2018, 3, 42-45.

28. Farrar, L. Gardens and Gardeners of the Ancient World_History, Myth \& Archaeology; Windgather Press/Oxbow Books: Oxford, UK, 2016.

29. Barbera, G.; Chieco, C.; Georgiadis, T.; Motisi, A.; Rossi, F. The "jardinu" of Pantelleria as a paradigm of respource-efficient horticulture in the built-up environment. Acta Hortic. 2018, 351-356.

30. Georgiadis, T.; Barbera, G.; Carotenuto, F.; Lenzi, J.; Motisi, A.; Rossi, F. How a traditional agricultural protection structure acts in conditioning the internal microclimate: A statistical analytical approach to Giardino Pantesco (Pantelleria Islan, Italy). Ital. J. Agrometeorol. 2014, 18, 41-58.

31. Barbera, G. The Elementary Garden. Archit. Paesaggio 2017, 34, 14-16.

32. Laureano, P. The System of Knowledge in the Mediterranean and Its Classification with Reference to Different Social Groupings-Report Prepared for the Secretariat of the Convention to Combat Desertification. In Proceedings of the United Nations Convention to Combat Desertification Conference-Committee on Science and Technology, Recife, Brazil, 16-18 November 1999; Available online: https://www.unccd.int/sites/ default/files/sessions/documents/ICCD_COP3_1/cstmisc1eng.pdf (accessed on 20 May 2020).

33. Hudson, J. Walled Gardens; National Trust Books: London, UK, 2018.

34. Fatio de Duiller, N. Fruit-Walls Improved, by Inclining Them to the Horizon: Or, a Way to Build Walls For Fruit-Trees; R. Everingham: London, UK, 1699.

35. Hall, E. Hot Walls: An Investigation of Their Construction in Some Northern Kitchen Gardens. Gard. Hist. 1989, 17, 95-107. [CrossRef]

36. Du Breuil, A. The Thomery System of Grape Culture; Geo, E., Ed.; Woodward \& Co.: New York, NY, USA, 1876; Available online: https://archive.org/details/thomerysystemofg00dubr/mode/2up (accessed on 20 May 2020).

37. Phin, J. Open Air Grape Culture: A Practical Treatise on the Garden and Vineyard Culture of Vine, and the Manufacture of Domestic Wine; Saxton, C.M., Ed.; Agricultural Book Publisher: New York, NY, USA, 1862; Available online: https://ia902606.us.archive.org/18/items/openairgrapecult00phinrich/openairgrapecult00phinrich.pdf (accessed on 20 May 2020).

38. Chastanet, M. An Old Horticultural System on the Doorstep of Paris: The "Peach Walls" of Montreuil. Available online: https://halshs.archives-ouvertes.fr/halshs-01341000v2/document (accessed on 20 May 2020).

39. Schabol, R.; Aubin, L. Discours sur Montreuil-Histoire des Murs à Pêches; Edition Lume; Montreuil-sous-Bois Horticultural Society: Montreuil, France, 2014.

40. Attlee, H. The Land Where Lemons Grow-The Story of Italy and Its Citrus Fruit; The Countryman Press: New York, NY, USA, 2014. 
41. Barontini, S.; Vitale, N.; Fausti, F.; Bettoni, B.; Bonati, S.; Peli, M.; Pietta, A.; Tononi, M.; Ranzi, R. The traditional irrigation technique of Lake Garda lemon-houses (Northern Italy). Eur. Geosci. Union Gen. Assem. 2016, 18, 14761.

42. Badiani, B.; Barontini, S.; Bettoni, B.; Bonati, S.; Peli, M.; Pietta, A.; Scala, B.; Tononi, M.; Vitale, N. Lake Garda lemon houses (Italy): Opportunities of a sensitive, marginal area in urban planning. Chang. Adapt. Socioecol. Syst. 2017, 3, 111-118. [CrossRef]

43. Biodiversity Indicators Partnership. Guidance for National Biodiversity Indicator Development and Use; UNEP World Conservation Monitoring Centre: Cambridge, UK, 2011; Available online: https://www.cbd.int/ doc/meetings/ind/ahteg-sp-ind-01/other/ahteg-sp-ind-01-bipnational-en.pdf (accessed on 25 June 2020).

44. Martin-López, B.; Gómez-Baggethun, E.; Garcia-Llorente, M.; Montes, C. Trade-offs across value-domains in ecosystem services assessment. Ecol. Indic. 2014, 37, 220-228. [CrossRef]

45. Science for Environment Policy. In-depth Reports. In The Multifunctionality of Green Infrastructure; European Commission's Directorate-General Environment: Bristol, UK, 2012.

46. Benke, K.; Tomkins, B. Future food-production systems: Vertical farming and controlled-environment agriculture. Sustain. Sci. Pract. Policy 2017, 13, 13-26. [CrossRef]

47. Sustainable Development Goals Knowledge Platform. Available online: https://sustainabledevelopment.un. org/?menu=1300 (accessed on 25 June 2020).

48. Hensel, M.; Santucci, D.; Sunguroğlu Hensel, D.; Auer, T. The Lampedusa Studio: A Multimethod Pedagogy for Tackling Compound Sustainability Problems in Architecture, Landscape Architecture, and Urban Design. Sustainability 2020, 12, 4369. [CrossRef]

(C) 2020 by the author. Licensee MDPI, Basel, Switzerland. This article is an open access article distributed under the terms and conditions of the Creative Commons Attribution (CC BY) license (http://creativecommons.org/licenses/by/4.0/). 